\title{
Whole Genome Enabled Phylogenetic and Secretome Analyses of Two Venturia nashicola Isolates
}

\author{
Maxim Prokchorchik $\mathbb{B}^{1 \dagger}{ }^{1 \dagger}$, Kyungho Won ${ }^{2 \dagger}$, Yoonyoung Lee $\mathbb{D}^{1}{ }^{1}$, Cécile Segonzac $\mathbb{D}^{3,4}$, and Kee Hoon Sohn ${ }^{10}{ }^{1,5 *}$ \\ ${ }^{I}$ Department of Life Sciences, Pohang University of Science and Technology, Pohang 37673, Korea \\ ${ }^{2}$ National Institute of Horticultural and Herbal Science (NIHHS), Rural Development Administration (RDA), Naju 58216, \\ Korea \\ ${ }^{3}$ Department of Plant Science, Plant Genomics and Breeding Institute and Research Institute of Agriculture and Life \\ Sciences, College of Agriculture and Life Sciences, Seoul National University, Seoul 08826, Korea \\ ${ }^{4}$ Plant Immunity Research Center, College of Agriculture and Life Sciences, Seoul National University, Seoul 08826, \\ Korea \\ ${ }^{5}$ School of Interdisciplinary Bioscience and Bioengineering, Pohang University of Science and Technology, Pohang \\ 37673, Korea
}

(Received on October 11, 2019; Revised on November 29, 2019; Accepted on December 10, 2019)

Venturia nashicola is a fungal pathogen causing scab disease in Asian pears. It is particularly important in the Northeast Asia region where Asian pears are intensively grown. Venturia nashicola causes disease in Asian pear but not in European pear. Due to the highly restricted host range of Venturia nashicola, it is hypothesized that the small secreted proteins deployed by the pathogen are responsible for the host determination. Here we report the whole genome based phylogenetic analysis and predicted secretomes for $V$. nashicola isolates. We believe that our data will provide a valuable information for further validation and functional char-

\footnotetext{
${ }^{\dagger}$ These authors contributed equally to this work.

*Corresponding author.

Phone) +82-54-279-2357, FAX) +82-54-279-2199

E-mail) khsohn@postech.ac.kr

ORCID

Maxim Prokchorchik

https://orcid.org/0000-0001-9118-6450

Yoonyoung Lee

https://orcid.org/0000-0002-5080-7633

Cécile Segonzac

https://orcid.org/0000-0002-5537-7556

Kee Hoon Sohn

https://orcid.org/0000-0002-9021-8649

(c) This is an Open Access article distributed under the terms of the Creative Commons Attribution Non-Commercial License (http:// creativecommons.org/licenses/by-nc/4.0) which permits unrestricted noncommercial use, distribution, and reproduction in any medium, provided the original work is properly cited.
}

Articles can be freely viewed online at www.ppjonline.org. acterization of host determinants in $V$. nashicola.

Keywords : effector analysis, phylogenetic analysis, Venturia nashicola

Handling Editor : Sook-Young Park

Venturia nashicola is a member of Venturiaceae family that includes several important fungal pathogens of plant Rosaceae family, such as Venturia inaequalis, $V$. pyrina, and $V$. carpophila (Ishii and Yanase, 2000; Tanaka and Yamamoto, 1964). Venturia nashicola causes scab disease in Asian pears and is considered as a serious threat to the Asian pear industry. So far there is no scab disease resistant Asian pear cultivar available to growers (Ishii and Yanase, 2000; Park et al., 2000). Even though some agro-materials were shown to suppress the growth and sporulation of $V$. nashicola, in the field conditions, this disease is controlled by multiple fungicide applications in each growing season (Park et al., 2000; Song and Seo, 2018). Recently, emergence of several cases of fungicide resistance development was reported for $V$. nashicola (Ishii, 2012; Kwak et al., 2017). This emphasizes the need for developing scab resistant Asian pear cultivars and better understanding of the interactions between pear and $V$. nashicola.

There are several members of Venturiaceae family known as scab-causing pathogens including Venturia inaequalis, V. nashicola, V. pyrina, V. carpophila, and V. effusa (Gonzalez-Dominguez et al., 2017). Interestingly, these 
species have distinct and narrow host range (Sivanesan, 1977). Venturia inaequalis, infecting apple but not pear, is the most studied species of Venturiaceae family (Bowen et al., 2011; MacHardy, 1996). Several genome analyses have been reported in recent years, providing a platform for development of scab resistant apple cultivars (Deng et al., 2017; Passey et al., 2018; Shiller et al., 2015). In contrast, significantly less effort was given on other Venturiaceae family members. Recently, draft genome sequence of Venturia pyrina which infects European pear but not Asian pear has been published (Deng et al., 2017). In addition, draft genomes of the peach scab causing fungus $V$. carpophila and pecan infecting $V$. effusa have been reported (Bock et al., 2016; Chen et al., 2017). More recently, genome sequences of several $V$. nashicola isolates have been presented (Johnson et al., 2019; Prokchorchik et al., 2019).

Plant pathogens deliver specific effector proteins into the host plant cells in order to promote virulence. On the other hand, plants have evolved specific immune receptors to recognize corresponding effector proteins directly or indirectly, and activate disease resistance (Jones and Dangl, 2006). To date, many effectors were discovered using genetic map-based cloning approach and proteome analysis in fungal and oomycete plant pathogens (Selin et al., 2016; Uhse and Djamei, 2018). In addition, recent progress on plant pathogen genomics enabled researchers to accelerate prediction of effectors. For example, comparative genom- ics approach helped to identify the Avel effector from a fungal pathogen Verticillium dahliae that is recognized in tomato plants carrying $\mathrm{Vel}$ disease resistance gene (de Jonge et al., 2012).

In $V$. inaequalis-Malus pathosystem, 17 genetically characterized disease resistance loci were reported (Bus et al., 2011). Of these, two resistance loci, Rvi6 and Rvi15, were studied in detail but the avirulence determinants from $V$. inaequalis have not been identified to date (Joshi et al., 2011; Schouten et al., 2014; Vinatzer et al., 2001). The genetic basis of scab resistance in Asian and European pears has not been fully established, although some molecular markers linked to scab resistance have been developed (Bouvier et al., 2012; Won et al., 2014).

In this study, we used the whole genome sequences of several major Venturiaceae species to reconstitute the phylogenetic relationships between them. Furthermore, we predicted the small secreted proteins that may function as virulence or avirulence effectors during host plant infection. The data presented in this study would be valuable to better understand the host-specific virulence mechanism of V. nashicola.

Previously we have sequenced and annotated the genomes of two Venturia nashicola isolates, MAFF615029 and PRI2 collected from Japan and Korea, respectively (Prokchorchik et al., 2019). To define their phylogenetic relationships to the other members of Venturia genus, we

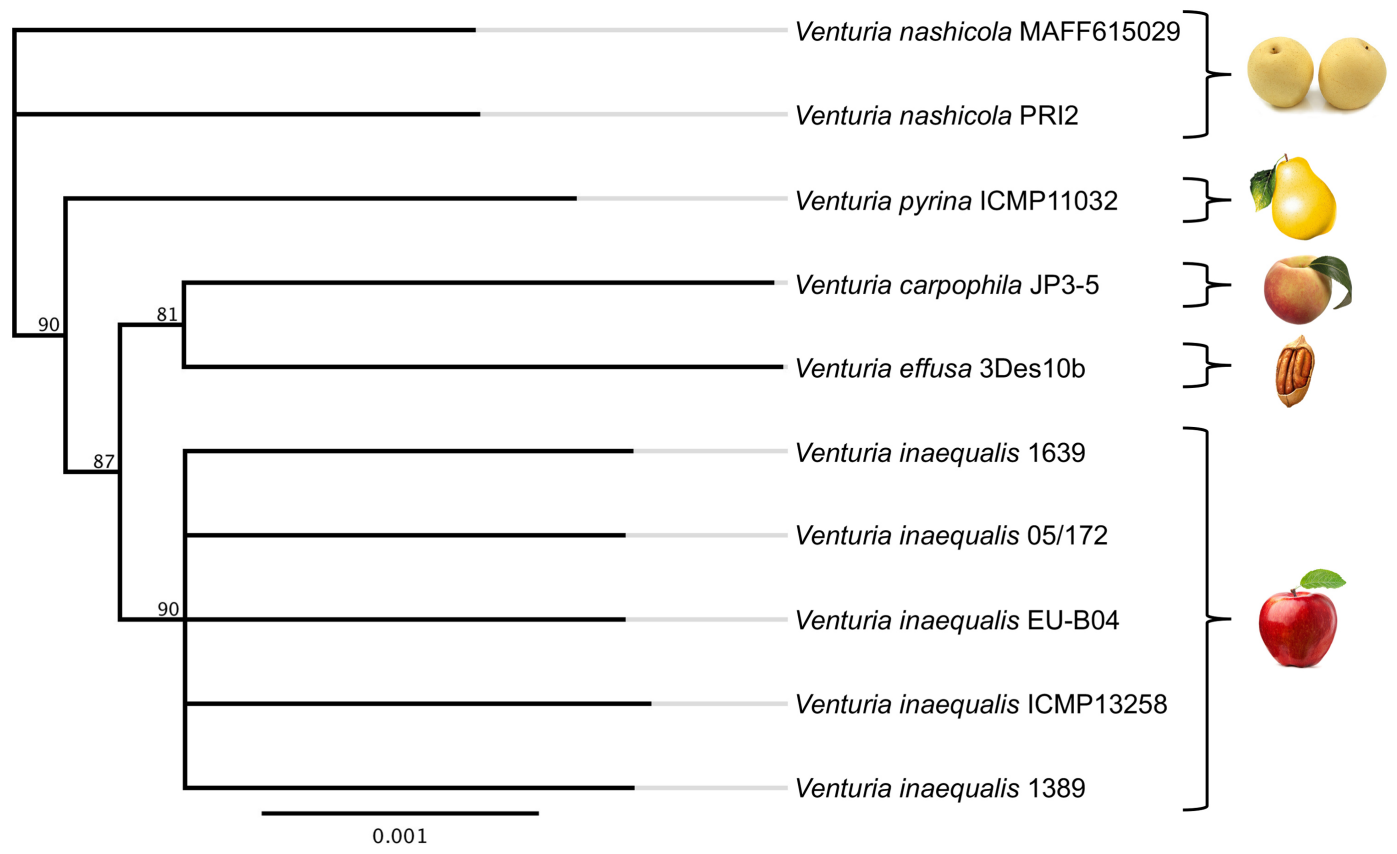

Fig. 1. Phylogenetic tree representing the relationships in the Venturia genus. Protein sequences of all the translated genes predicted in the strains were clustered and total 6,650 conserved cluster trees were used to build a majority rule consensus tree with $70 \%$ branch support threshold. Bootstrap branch support is provided as node labels. 
aimed to construct a phylogenetic tree consisting of the strains for which whole genome sequence is available. As our study focuses on very closely related Venturia isolates we aimed to use the whole genome level data in order to be able to reliably resolve the closest relatives, which is in contrast to limited gene set alignments used previously for phylogenetic analysis (Yun et al., 2013; Zhao et al., 2012). We used whole genome predicted protein sets of 10 Venturia isolates for constructing phylogenetic tree. The protein sets were either retrieved from Mycocosm database (https://genome.jgi.doe.gov/mycocosm/home) for $V$. pyrina ICMP11032 and $V$. inaequalis ICMP13258, or generated in-house using Fungap pipeline applied to genome sequences of $V$. carpophila JP3-5 (NCBI BioProject: PRJNA321389), $V$. effusa 3Des10b (NCBI BioProject: PRJNA285422), $V$. inaequalis 1389 (NCBI BioProject: PRJNA261633), $V$. inaequalis 1639 (NCBI BioProject: PRJNA261633), $V$. inaequalis EU-B04 (NCBI BioProject: PRJNA407103), and $V$. inaequalis 05/172 (NCBI BioPro- ject: PRJNA354841). Protein sequences of all the genes annotated in the Venturia isolates were clustered using OrthoMCl v2.0.9 software (Li et al., 2003) with BLAST evalue $10^{-7}$. Only clusters conserved in all the isolates were considered for phylogenetic analysis (total 6,650 clusters). Hidden Markov Model (HMM) profiles of each gene cluster were built using HMMER3 v3.2.1 (Mistry et al., 2013). These were then compared between strains and neighborjoining phylogenetic trees were built based on these comparisons using the pHMM-Tree (Huo et al., 2017). Each tree was bootstrapped 100 times and the best tree was used for further analysis. All cluster trees were used to build a majority rule consensus super tree with $70 \%$ branch support threshold using Geneious Prime 2019.04 (Fig. 1). Similar to recent studies (Yun et al., 2013; Zhao et al., 2012), the five $V$. inaequalis isolates were grouped together and $V$. nashicola isolates analyzed in this study showed close relationship to $V$. pyrina (Fig. 1). These data indicate that $V$. pyrina and $V$. nashicola form a separate clade from
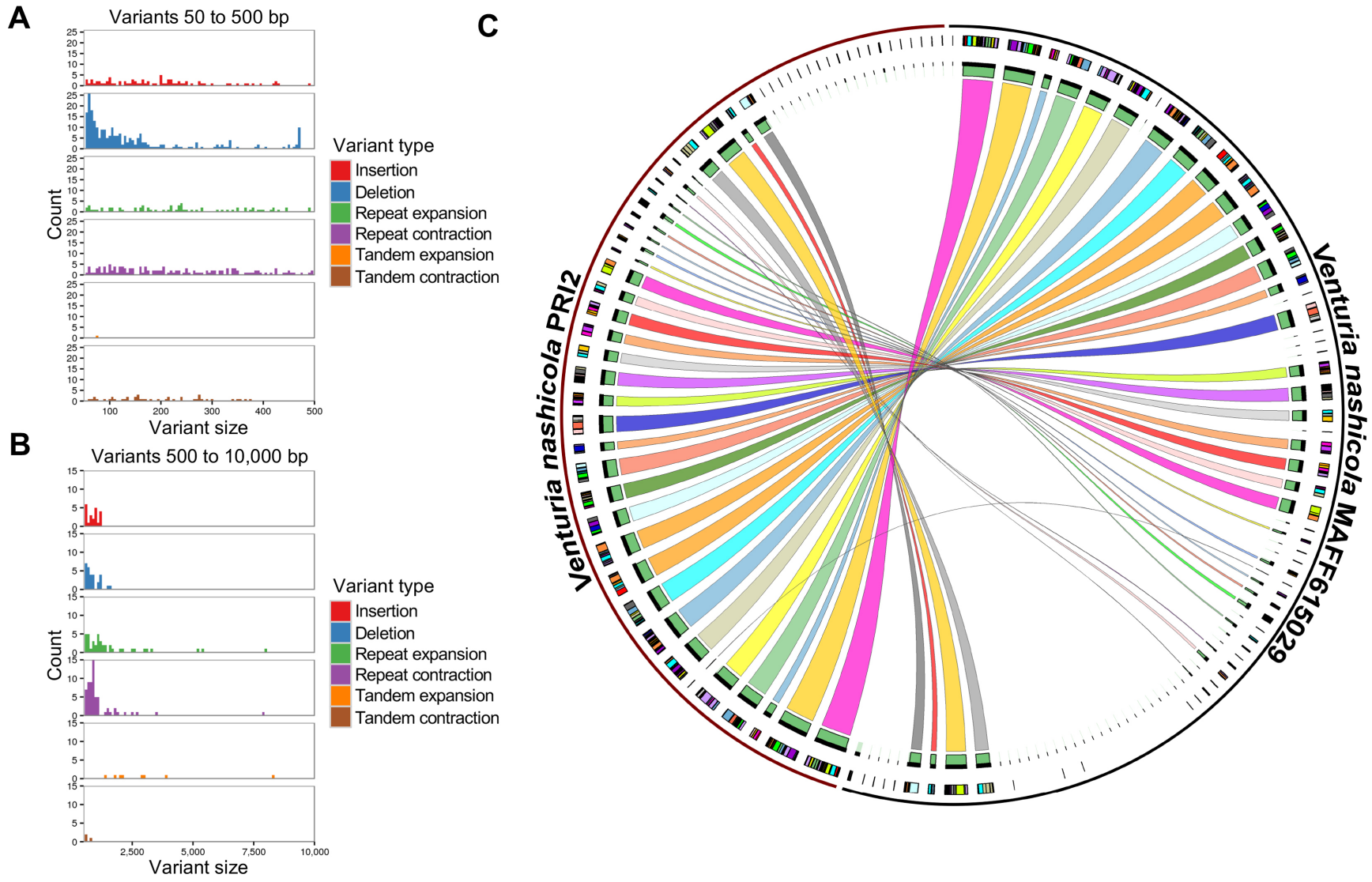

Fig. 2. Whole genome comparison of Venturia nashicola PRI2 and MAFF615029 confirms their close relation to each other. (A) Small genetic variants analysis shows that deletions are the most common of small genetic variants. Analysis was performed using NucMer and visualized by Assemblytics. (B) Larger genetic variants are are abundant to similar extent. Analysis was performed as described in A. (C) Whole-genome comparison of assembled contigs of $V$. nashicola isolates reveals no large genomic re-arrangements. Genomes were analyzed with Sibelia and results were visualized with Circos. 
$V$. inaequalis isolates (Fig. 1).

In order to further confirm the genetic relatedness of $V$. naschicola MAFF615029 and PRI2 isolates, we performed a whole genome comparison. We first aimed to discover single nucleotide polymorphisms (SNPs) using Snippy (v. 4.3.8) (Seemann, 2015). To begin with, comparison between $V$. nashicola MAFF615029 and PRI2 only was run, then Snippy was run in pairwise manner comparing different Venturia isolates to $V$. nashicola MAFF615029. Finally, snippy core command was used to call the core SNPs between all the strains compared. We could identify total 105,564 SNPs when comparing the MAFF615029 and PRI2 isolates only. To compare the amount of SNPs between more distant relatives of $V$. nashicola we generated the core SNPs shared in all the genomes compared to $V$. nashicola MAFF615029. We could identify 542 core SNPs when comparing MAFF615029 and PRI2, 14,304 SNPs when comparing $V$. nashicola MAFF615029 and $V$. pyrina, 35,549 SNPs when comparing $V$. nashicola MAFF615029 and $V$. inaequalis ICMP13258, 46,735 SNPs when comparing $V$. nashicola MAFF615029 and $V$. effusa and 48,263 SNPs when comparing $V$. nashicola MAFF615029 to $V$. carpophila. These results confirmed the close relation of $V$. nashicola strains between each other suggested by our phylogenetic analysis.

We further performed structural genome variations discovery in PRI2 genome in comparison to MAFF615029 isolate. We used NucMer with following parameters '-maxmatch -1 100 -c 500' (Delcher et al., 2002) and then visualized using Assemblytics (Nattestad and Schatz, 2016). We could identify 777 significant variants. Majority of them were small, mostly 50-500 nucleotides (nt) deletions and, interestingly, insertions, deletions, repeat expansions and contractions were represented relatively equally among more significant (500-10,000 bp) variants (Fig. 2A and B). However, this could be the consequence of shortread assembly of PRI2 isolate genome.

Next, we analyzed $V$. nashicola MAFF615029 and PRI2 genomes for larger genomic re-arrangements. For that we used Sibelia with following parameters '-s fine -q -v --gff --correctboundaries' (Minkin et al., 2013) and visualized the results using Circos (Krzywinski et al., 2009). There were no large genomic rearrangements detected inside the large scaffolds (Fig. 2C). Overall the genomes surveyed show very high similarity to each other and most of the differences are located in the unaligned short scaffolds. For example, there are 21 predicted genes in $V$. nashicola PRI2 and there are 586 predicted genes in $V$. nashicola MAFF615029 located in such scaffolds.

Bioinformatic prediction of effectors may help to iden-

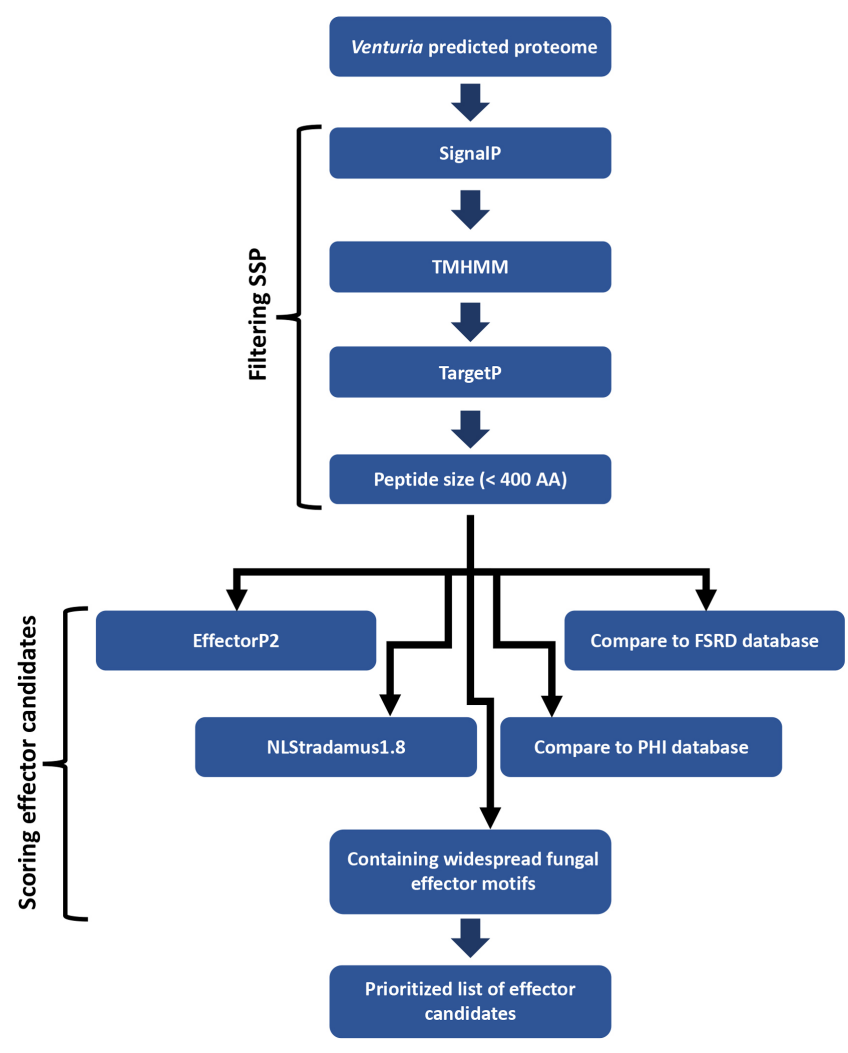

Fig. 3. A schematic representation of the effector prediction pipeline used in this study. The descriptions and sources of these programs are indicated in main text.

tify the virulence and avirulence determinants in fungal species. We used a pipeline for effector annotation based on multiple criteria outlined in Fig. 3. Predicted genes were translated and checked for the presence of signal peptide using SignalP v4.1 (Nielsen, 2017). Proteins with predicted signal peptides were further surveyed for the absence of transmembrane helices using TMHMM (Krogh et al., 2001). All the proteins longer than 400 AA were removed and the short-listed proteins were further assessed for potential targeting in the plant cell using TargetP (Emanuelsson et al., 2007). Resulting set of proteins was subjected to several analyses to score and prioritize effector candidates. In short, the short-listed candidates were subjected to EffectorP2 analysis (Sperschneider et al., 2018) and each effector candidate was assigned a score between 0 and 10 based on the effector prediction confidence. Some fungal and oomycete effectors were shown to be localized to the plant cell nucleus (Ahmed et al., 2018; Vargas et al., 2016) and therefore the short-listed candidates were evaluated for the presence of nuclear localization signal (NLS) using NLStradamus (Nguyen Ba et al., 2009), based on the NLS prediction confidence a score from 0 to 5 was assigned. In 

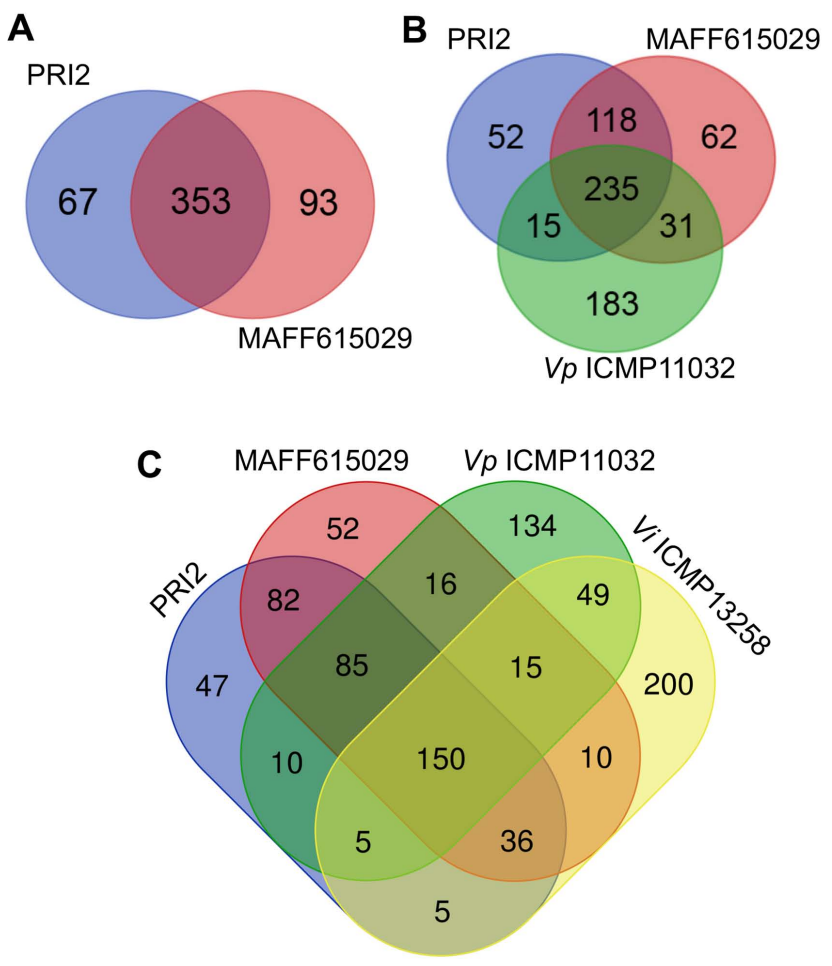

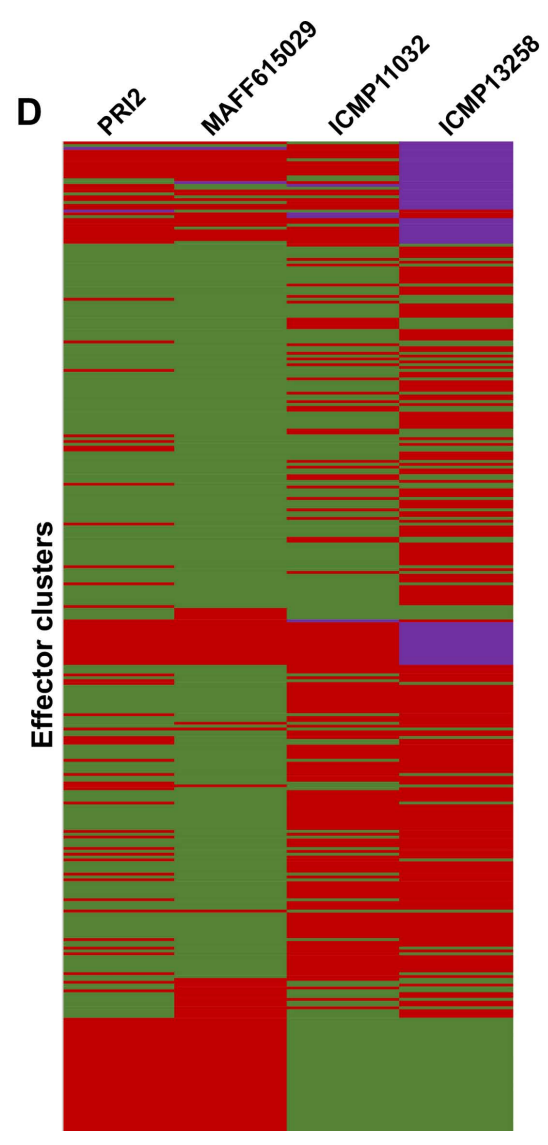

Fig. 4. Effector repertoires of Venturia nashicola isolates in comparison to $V$. inaequalis and $V$. pyrina. (A) Effector families presence overlap between $V$. nashicola PRI2 and MAFF615029 isolates able to infect Asian pear cultivars. (B) Effector families presence overlap between $V$. nashicola PRI2, MAFF615029 isolates which are able to infect Asian pear cultivars and $V$. pyrina ICMP11032 able to infect European pear cultivars. (C) Effector families overlap between $V$. nashicola PRI2 and MAFF615029 isolates which are able to infect Asian pear cultivars and $V$. pyrina ICMP11032 and $V$. inaequalis ICMP13258, infecting European pear and apple respectively. (D) Table representing the presence and absence of putative effector families in Venturia nashicola, $V$. pyrina and $V$. inaequalis isolates. Green or red color indicates presence or absence of effector gene, respectively. Purple color indicates the presence of multiple orthologous effector genes. The putative effector families that are commonly present in all 4 isolates are not shown.

addition, short-listed proteins were blasted against Fungal Stress Related Database (FSRD) (Karányi et al., 2013) and PHI-base (Pathogen-Host Interaction database) (Urban et al., 2017) databases. Depending on BLAST hit coverage and similarity level a score from 0 to 10 was assigned for comparison with each of two databases. Finally, shortlisted proteins were assessed for the known fungal/oomycete effector motifs, such as RxLR, DEER, RxLX[EDQ], [KRHQSA][DENQ]EL, [Y/W]xC, RSIVEQD (Sonah et al., 2016) using a custom python script and a score from 0 to 6 was assigned. A sum of individual tool scores was used as an integrated effector prediction confidence score and was used to rank the effector candidates in a final short-list. Effector candidates with overall score 0 were discarded from the final short-list. As the results we identified the following numbers of potential effectors in Venturia strains analyzed: V. nashicola MAFF615029, 451; V. nashicola PRI2, 424; V. pyrina ICMP11032, 477; and $V$. inaequalis ICMP13258, 673 (see Supplementary Tables 1-4, Supplementary FASTA-files 1-4). We focused on these 4 representative isolates in order to identify the putative effectors that are specific to the Venturia species infecting European pear, Asian pear or apple. The putative effectors were clustered using OrthoMCL v2.0.9 with BLAST e-value of $10^{-7}$ and resulting effector families and single effector genes were assessed for presence or absence in the Venturia strains. We identified the core effector repertoire of two $V$. nashicola strains as 353 conserved effectors (Fig. 4A). When we expanded effector comparison to include two strains of $V$. nashicola and one $V$. pyrina strain, 
we could identify 235 core effectors. In addition to core effectors we identified 118 potential effectors specific to $V$. nashicola strains and 183 potential effectors specific to $V$. pyrina (Fig. 4B). These putative effectors may act as hostrange determinants between $V$. nashicola and $V$. pyrina enabling an avirulent recognition in non-host plant species. Finally, we expanded the effector comparison to include $V$. inaequalis ICMP13258 putative effectors. In this case we could identify 150 prospective core effectors for Venturia genus and 82 effector families specific for $V$. nashicola strains infecting Asian pear (see Supplementary Table 5), 134 effector families specific for $V$. pyrina infecting European pear (see Supplementary Table 6) and 200 effector families specific for $V$. inaequalis infecting apple (Fig. 4C, Supplementary Table 7). Overall presence and absence patterns of effector families in repertoires of $V$. nashicola, $V$. pyrina and $V$. inaequlis seem to correlate with the host range of the pathogen (Fig. 4D).

Based on our sequencing data we were able to analyze the phylogeny of representative isolates of Venturia genus using the whole genome supertree approach. We also employed the information from multiple gene clusters using the HMM profile comparison instead of protein alignment of single copy genes. Overall, our phylogenetic tree supports the phylogenetic analysis reported previously (Yun et al., 2013; Zhao et al., 2012). We also confirm a close relation between $V$. nashicola and $V$. pyrina species.

Fungal effector prediction is one of the most challenging tasks in contemporary plant pathology research. Availability of whole genome assemblies and utilizing a range of computational tools should increase the effector prediction sensitivity. Here we used integrated approach for identifying effectors where results of different analytic tools are evaluated to rank and shortlist the effector candidates for further analysis. We analyzed the presence of effector families in various Venturia species infecting different plant hosts. This provides a valuable resource for future research aiming to confirm effectors that play important roles in host specialization of Venturia species.

\section{Acknowledgments}

This work was carried out with the support of "Cooperative Research Program for Agriculture Science \& Technology Development (Project No. PJ01191301)" Rural Development Administration and Next-Generation BioGreen 21 Program (Plant Molecular Breeding) of Rural Development Administration (PJ01317501), Republic of Korea. C.S. is supported by the Creative-Pioneering Researchers Program through Seoul National University.

\section{Electronic Supplementary Material}

Supplementary materials are available at Plant Pathology Journal website (http://www.ppjonline.org/).

\section{References}

Ahmed, M. B., Santos, K. C. G. D., Sanchez, I. B., Petre, B., Lorrain, C., Plourde, M. B., Duplessis, S., Desgagné-Penix, I. and Germain, H. 2018. A rust fungal effector binds plant DNA and modulates transcription. Sci. Rep. 8:14718.

Bock, C. H., Chen, C., Yu, F., Stevenson, K. L. and Wood, B. W. 2016. Draft genome sequence of Fusicladium effusum, cause of pecan scab. Stand. Genomic Sci. 11:36.

Bouvier, L., Bourcy, M., Boulay, M., Tellier, M., Guérif, P., Denancé, C., Durel, C.-E. and Lespinasse, Y. 2012. A new pear scab resistance gene Rvp1 from the European pear cultivar 'Navara' maps in a genomic region syntenic to an apple scab resistance gene cluster on linkage group 2. Tree Genet. Genomes 8:53-60.

Bowen, J. K., Mesarich, C. H., Bus, V. G. M., Beresford, R. M., Plummer, K. M. and Templeton, M. D. 2011. Venturia inaequalis: the causal agent of apple scab. Mol. Plant Pathol. 12:105-122.

Bus, V. G. M., Rikkerink, E. H. A., Caffier, V., Durel, C.-E. and Plummer, K. M. 2011. Revision of the nomenclature of the differential host-pathogen interactions of Venturia inaequalis and Malus. Annu. Rev. Phytopathol. 49:391-413.

Chen, C., Bock, C. H. and Wood, B. W. 2017. Draft genome sequence of Venturia carpophila, the causal agent of peach scab. Stand. Genomic Sci. 12:68.

de Jonge, R., van Esse, H. P., Maruthachalam, K., Bolton, M. D., Santhanam, P., Saber, M. K., Zhang, Z., Usami, T., Lievens, B., Subbarao, K. V. and Thomma, B. P. 2012. Tomato immune receptor Ve1 recognizes effector of multiple fungal pathogens uncovered by genome and RNA sequencing. Proc. Natl. Acad. Sci. U. S. A. 109:5110-5115.

Delcher, A. L., Phillippy, A., Carlton, J. and Salzberg, S. L. 2002. Fast algorithms for large-scale genome alignment and comparison. Nucleic Acids Res. 30:2478-2483.

Deng, C. H., Plummer, K. M., Jones, D. A. B., Mesarich, C. H., Shiller, J., Taranto, A. P., Robinson, A. J., Kastner, P., Hall, N. E., Templeton, M. D. and Bowen, J. K. 2017. Comparative analysis of the predicted secretomes of Rosaceae scab pathogens Venturia inaequalis and $V$. pirina reveals expanded effector families and putative determinants of host range. $B M C$ Genomics 18:339.

Emanuelsson, O., Brunak, S., von Heijne, G. and Nielsen, H. 2007. Locating proteins in the cell using TargetP, SignalP and related tools. Nat. Protoc. 2:953-971.

González-Domínguez, E., Armengol, J. and Rossi, V. 2017. Biology and epidemiology of Venturia species affecting fruit crops: a review. Front. Plant Sci. 8:1496.

Huo, L., Zhang, H., Huo, X., Yang, Y., Li, X. and Yin, Y. 2017. 
pHMM-tree: phylogeny of profile hidden Markov models. Bioinformatics 33:1093-1095.

Ishii, H. 2012. Resistance in Venturia nashicola to benzimidazoles and sterol demethylation inhibitors. In: Fungicide resistance in crop protection: risk and management, ed. by T. S. Thind, pp. 21-31. CAB International, Wallingford, UK.

Ishii, H. and Yanase, H. 2000. Venturia nashicola, the scab fungus of Japanese and Chinese pears: a species distinct from $V$. pirina. Mycol. Res. 104:755-759.

Johnson, S., Jones, D., Thrimawithana, A. H., Deng, C. H., Bowen, J. K., Mesarich, C. H., Ishii, H., Won, K., Bus, V. G. M. and Plummer, K. M. 2019. Whole genome sequence resource of the Asian pear scab pathogen Venturia nashicola. Mol. Plant-Microbe Interact. 32:1463-1467.

Jones, J. D. G. and Dangl, J. L. 2006. The plant immune system. Nature 444:323-329.

Joshi, S. G., Schaart, J. G., Groenwold, R., Jacobsen, E., Schouten, H. J. and Krens, F. A. 2011. Functional analysis and expression profiling of HcrVfl and HcrVf2 for development of scab resistant cisgenic and intragenic apples. Plant Mol. Biol. 75:579-591.

Karányi, Z., Holb, I., Hornok, L., Pócsi, I. and Miskei, M. 2013. FSRD: fungal stress response database. Database (Oxford) 2013:bat037.

Krogh, A., Larsson, B., von Heijne, G. and Sonnhammer, E. L. 2001. Predicting transmembrane protein topology with a hidden Markov model: application to complete genomes. J. Mol. Biol. 305:567-580.

Krzywinski, M., Schein, J., Birol, I., Connors, J., Gascoyne, R., Horsman, D., Jones, S. J. and Marra, M. A. 2009. Circos: an information aesthetic for comparative genomics. Genome Res. 19:1639-1645.

Kwak, Y., Min, J., Song, J., Kim, M., Lee, H. and Kim, H. T. 2017. Relationship of resistance to benzimidazole fungicides with mutation of $\beta$-tubulin gene in Venturia nashicola. Res. Plant Dis. 23:150-158 (in Korean).

Li, L., Stoeckert, C. J. Jr. and Roos, D. S. 2003. OrthoMCL: identification of ortholog groups for eukaryotic genomes. Genome Res. 13:2178-2189.

MacHardy, W. E. 1996. Apple scab: biology, epidemiology, and management. American Phytopathological Society, St. Paul, MN, USA. 570 pp.

Minkin, I., Patel, A., Kolmogorov, M., Vyahhi, N. and Pham, S. 2013. Sibelia: a scalable and comprehensive synteny block generation tool for closely related microbial genomes. In: Lecture notes in computer science, Vol. 8126. Algorithms in bioinformatics. 13th International workshop, WABI 2013, eds. by A. Darling and J. Stoye, pp. 215-229. Springer-Verlag Berlin Heidelberg, Berlin, Heidelberg, Germany.

Mistry, J., Finn, R. D., Eddy, S. R., Bateman, A. and Punta, M. 2013. Challenges in homology search: HMMER3 and convergent evolution of coiled-coil regions. Nucleic Acids Res. 41:e121.

Nattestad, M. and Schatz, M. C. 2016. Assemblytics: a web analytics tool for the detection of variants from an assembly. Bioinformatics 32:3021-3023.

Nguyen Ba, A. N., Pogoutse, A., Provart, N. and Moses, A. M. 2009. NLStradamus: a simple Hidden Markov Model for nuclear localization signal prediction. BMC Bioinformatics 10:202.

Nielsen, H. 2017. Predicting secretory proteins with SignalP. In: Methods in molecular biology, Vol. 1611. Protein function prediction, ed. by D. Kihara, pp. 59-73. Humana Press, New York, NY, USA.

Park, P., Ishii, H., Adachi, Y., Kanematsu, S., Ieki, H. and Umemoto, S. 2000. Infection behavior of Venturia nashicola, the cause of scab on Asian pears. Phytopathology 90:12091216.

Passey, T. A. J., Armitage, A. D. and Xu, X. 2018. Annotated draft genome sequence of the apple scab pathogen Venturia inaequalis. Microbiol. Resour. Announc. 7:e01062-18.

Prokchorchik, M., Won, K., Lee, Y., Choi, E. D., Segonzac, C. and Sohn, K. H. 2019. High contiguity whole genome sequence and gene annotation resource for two Venturia nashicola isolates. Mol. Plant-Microbe Interact. 32:1091-1094.

Schouten, H. J., Brinkhuis, J., van der Burgh, A., Schaart, J. G., Groenwold, R., Broggini, G. A. L. and Gessler, C. 2014. Cloning and functional characterization of the Rvi15 ( $\mathrm{Vr} 2$ ) gene for apple scab resistance. Tree Genet. Genomes 10:251260.

Seemann, T. 2015. Snippy: rapid haploid variant calling and core genome alignment. URL https:/github.com/tseemann/snippy [11 October 2019].

Selin, C., de Kievit, T. R., Belmonte, M. F. and Fernando, W. G. D. 2016. Elucidating the role of effectors in plant-fungal interactions: progress and challenges. Front. Microbiol. 7:600.

Shiller, J., Van de Wouw, A. P., Taranto, A. P., Bowen, J. K., Dubois, D., Robinson, A., Deng, C. H. and Plummer, K. M. 2015. A large family of AvrLm6-like genes in the apple and pear scab pathogens, Venturia inaequalis and Venturia pirina. Front. Plant Sci. 6:980.

Sivanesan, A. 1977. Bibliotheca mycologica, Vol. 59. The taxonomy and pathology of Venturia species. J. Cramer, Vaduz, Germany. 139 pp.

Sonah, H., Deshmukh, R. K. and Bélanger, R. R. 2016. Computational prediction of effector proteins in fungi: opportunities and challenges. Front. Plant Sci. 7:126.

Song, J. and Seo, H.-J. 2018. Antifungal activity of agro-materials against pear scab (Venturia nashicola) and pear rust (Gymnosporangium asiaticum) fungi. Res. Plant Dis. 24:33-40 (in Korean).

Sperschneider, J., Dodds, P. N., Gardiner, D. M., Singh, K. B. and Taylor, J. M. 2018. Improved prediction of fungal effector proteins from secretomes with EffectorP 2.0. Mol. Plant Pathol. 19:2094-2110.

Tanaka, S. and Yamamoto, S. 1964. Studies on pear scab II. Taxonomy of the causal fungus of Japanese pear scab. Jpn. J. Phytopathol. 29:128-136 (in Japanese). 
Uhse, S. and Djamei, A. 2018. Effectors of plant-colonizing fungi and beyond. PLoS Pathog. 14:e1006992.

Urban, M., Cuzick, A., Rutherford, K., Irvine, A., Pedro, H., Pant, R., Sadanadan, V., Khamari, L., Billal, S., Mohanty, S. and Hammond-Kosack, K. E. 2017. PHI-base: a new interface and further additions for the multi-species pathogen-host interactions database. Nucleic Acids Res. 45:D604-D610.

Vargas, W. A., Sanz-Martín, J. M., Rech, G. E., Armijos-Jaramillo, V. D., Rivera, L. P., Echeverria, M. M., Díaz-Mínguez, J. M., Thon, M. R. and Sukno, S. A. 2016. A fungal effector with host nuclear localization and DNA-binding properties is required for maize anthracnose development. Mol. PlantMicrobe Interact. 29:83-95.

Vinatzer, B. A., Patocchi, A., Gianfranceschi, L., Tartarini, S., Zhang, H. B., Gessler, C. and Sansavini, S. 2001. Apple contains receptor-like genes homologous to the Cladospo- rium fulvum resistance gene family of tomato with a cluster of genes cosegregating with $V f$ apple scab resistance. Mol. Plant-Microbe Interact. 14:508-515.

Won, K., Bastiaanse, H., Kim, Y. K., Song, J. H., Kang, S. S., Lee, H. C., Cho, K. H., Brewer, L., Singla, G., Gardiner, S. E., Chagné, D. and Bus, V. G. M. 2014. Genetic mapping of polygenic scab (Venturia pirina) resistance in an interspecific pear family. Mol. Breed. 34:2179-2189.

Yun, Y. H., Yoon, S. K., Son, S. Y. and Kim, S. H. 2013. Homology of scytalone dehydratase melanin gene in Venturia nashicola. Korean J. Mycol. 41:200-204 (in Korean).

Zhao, P., Kakishima, M., Uzuhashi, S. and Ishii, H. 2012. Multigene phylogenetic analysis of inter- and intraspecific relationships in Venturia nashicola and V. pirina. Eur. J. Plant Pathol. 132:245-258. 